\title{
América Latina y la influencia de losmodelos políticos europeos en los años $80^{*}$
}

América Latina no ha sido ajena a las experiencias de los modelos políticos europeos, incluyendo los socialistas. En el pasado hubo ideas y movimientos socialistas; actualmente, hay ciertos regímenes que se dicen socialistas, como asimismo movimientos y esperanzas de carácter socialista.

Tampoco puede decirse que las experiencias socialistas de otras regiones hayan sido ajenas a la política latinoamericana. La revolución rusa de 1917 tuvo grandes repercusiones en el continente. México, incluso antes de la revolución bolchevique, se agitó de norte a sur en luchas campesinas y en reivindicaciones socialistas, hasta en las regiones más alejadas, como Yucatán. Actualmente, quienes se adentran en la historia mexicana se asombran de ver cuánta fuerza social renovadora hubo en la revolución de aquel país, y cuántos fueron los contactos y las influencias entre las luchas sociales continuas en México y la posterior revolución rusa.

Las experiencias del Frente Popular francés sirvieron de estímulo para los chilenos en la época del Presidente Aguirre Cerda, y la historia social y política de los trabajadores latinoamericanos siempre estuvo entremezclada con lo que ocurría en la lejana Europa. Más recientemente, la revolución china repercutió desde el Río Grande, en la frontera con los Estados Unidos, hasta la Patagonia.

Por otro lado, en el Chile de la Unidad Popular y del Presidente Allende, la discusión política giró en gran medida en torno al dilema que acosó a los socialistas europeos tras la segunda internacional: ¿reforma o revolución? La experiencia más próxima, la de Cuba, construida a partir de la saga guerrillera, penetró profundamente en la imaginación política de la izquierda. En Chile, no se sabía con certidumbre a qué tradición apelar: si a las Iuchas iniciadas con la toma del Palacio de Invierno, de raíz bolchevique, o al son continuo de la versión moderna de la revolución permanente,

* Este trabajo formará parte del libro de Cardoso, F. H. y Trindade, H. (compiladores), O novo socialismo frances e a América Latina, São Paulo, Paz e Terra, 1982. 
contrapunteada sordamente por los tambores de "uno, dos, tres, muchos Vietnams", o, en forma más europea y occidental, al encuentro entre el eurocomunismo y la tradición de socialismo no reformista pero tampoco guerrillero, que nunca fue sino un proyecto en la misma Europa.

¿Acaso la victoria de Mitterrand no habrá abierto de repente una vía (aunque no haya sido en la práctica) para dar consistencia a este último tipo de tradición socialista?

Si así fuera, ¿servirá esta vía como modelo político (o, en caso contrario, al menos como fuente inspiradora) para los países de un continente que siendo como es una extensión de la vieja Europa y también de los Estados Unidos, es sobre todo una parte (en parte) del Tercer Mundo?

Al lado de personas más doctas y conocedoras de la materia, no me atrevería siquiera a aventurar una suposición acerca del real significado de la experiencia del socialismo en Francia. Me limito a observar que la coyuntura política francesa parece haber sorprendido a los propios franceses, que todavía están enredados en el debate acerca de la alianza entre socialistas y comunistas. Aparentemente, antes que discutir los rumbos de la política de Mitterrand y de sus seguidores, los franceses se interesan por resolver la contradicción de la alianza de los socialistas con un partido comunista de profundas raíces autoritarias y que toma partido contra Solidaridad (al revés de lo que hace el partido comunista italiano). La disputa, por lo tanto, es sobre quién ejercerá la hegemonía en el campo de la izquierda. Aún así, como muestra Rouquié, en el plano internacional la posición socialista implica un importante cambio de Francia, y, como señala Touraine, el socialismo francés, quiéralo o no, debe definirse en el campo de una sociedad (denominada por él postindustrial), que ya no se constituye como aquellas cuyo análisis sirvió de base a los clásicos, sobre todo a Marx. Por lo tanto, el socialismo o innova o fracasa.

Sin embargo, me aventuraré a plantear otra pregunta: thasta qué punto cabe imaginar, hoy, que una transformación como la sucedida en Francia habrá de tener influencias sobre "les pays de la-bas"?

No se hace la pregunta suponiendo que Francia, como polo de atracción cultural haya perdido influencia, o que soluciones políticas propias, por atrayentes que puedan ser, hayan sustituido no sóto el mimetismo cultural, especialmente en la izquierda, sino también la porosidad de las élites y de las masas latinoamericanas ante las influencias externas. Pienso, más bien, en la situación estructural de las sociedades latinoamericanas comparadas con la de Francia, independientemente de las corrientes de opinión y del efecto de dinamización ideológica a que podría dar origen el éxito de una experiencia francesa. 
Sin embargo, antes de atacar frontalmente esta cuestión -la de la posibilidad de un tipo de solución socialista a la Mitterrand frente a las peculiaridades del desarrollo social y económico latinoamericano- convendria hacer algunas consideraciones, por impresionistas que sean, sobre cómo andamos en América Latina en lo que respecta a la comprensión, por parte de las izquierdas, de lo que es el socialismo europeo, y de su evaluación en el plano ideológico.

Es innegable que en la década de 1970 e inicios de la siguiente, la mayor parte de las izquierdas latinoamericanas reflexiona, reacciona y piensa sus cuestiones políticas prácticas a partir de tres experiencias que dejaron honda huella:

-la revolución cubana de 1958 y la implantación del socialismo de ahí en adelante;

-la experiencia de "transición al socialismo" de Chile en la Unidad Popular, entre 1970 y 1973 ;

-la caída de Somoza y la experiencia actual del frente sandinista en Nicaragua.

Fuera de estos pocos hechos, el resto fueron tentativas restringidas o fracasadas. Fracasó el trasplante de la experiencia guerrillera cubana a Bolivia, Venezuela, Colombia, Perú y regiones centroamericanas; fracasó la combinación de frente populista con guerriIla montonera y trotskismo en Argentina; fracasó el movimiento tupamaro en Uruguay; fracasó la embrionaria lucha armada en Brasil; fracasó el movimiento del período de Torres, en Bolivia.

A este rosario de desilusiones se suman, aquí y allá, los llamados "avances democráticos", como los de República Dominicana, y algunas otras experiencias, ya sea la de mantener alguna forma de régimen constitucional tras períodos de autoritarismo militar (Perú), - la evitar que la arbitrariedad domine completamente la escena política, como en el caso del Brasil tras la liberalización conservadora de 1978.

Puesto que los procesos a que hace referencia el párrafo anterior no llegaron ni siquiera a plantear la cuestión del socialismo, pues apenas si plantean la cuestión de la preservación de los derechos humanos, $y$, en los casos más logrados, la del Estado de Derecho, es natural que la conciencia socialista latinoamericana deba contentarse con debatir, exaltar o criticar las tres experiencias próximas más consistentes en ei sentido de un camino socialista: Guba, èl Chile de Allende y la experiencia sandinista.

Sin embargo, entre estas tres, el camino de la "transición democrática al socialismo" en Chile terminó en la forma de todos conocida; el frente sandinista tiene mucho en común con los movimien- 
tos de tipo "lucha de todo el pueblo por la liberación nacional". Sólo queda Cuba, cuya experiencia produce entre los socialistas, al mismo tiempo, una reacción de simpatía y de perplejidad; simpatía, pues bien o ral las cuestiones relacionadas con el bienestar de la población van resolviéndose; y perplejidad, puesto que es difícil aceptar sin cuestionamiento lo relativo a la participación de la masa en el poder y su control, lo que en sentido amplio tiene que ver con las garantías efectivas de libertad política, cultural y personal.

Más serio aún: puesto que los caminos prácticos para el socialismo, con las excepciones mencionadas, fueron suprimidos violentamente por la reacción local e internacional o apenas si fueron vislumbrados por la mayoría de las poblaciones locales, el debate acerca de ellos adquirió contornos ideológico-subjetivos. Primó el replanteamiento, en términos agónicos, de la antigua cuestión acerca de "reforma" o "revolución", pensadas una y otra de manera abstracta y teniendo como contexto algo ajeno a la experiencia local: el cuadro histórico de la lucha entre la Segunda y la Tercera Internacional, quedando la Guarta con los dientes afilados para criticar por encima del hombro ambas (con la discutible ventaja de que ninguna experiencia histórica concreta fue de hecho conducida por sus seguidores...).

Frente a este cuadro, el observador de la escena política latinoamericana se queda con la sensación de que se ha derramado mucha tinta en la izquierda, como también alguna sangre preciosa (tal vez más en los subterráneos de la represión que en el campo abierto de la lucha), y que hay muchas voces que claman por días mejores, sin que se recorra un camino viable de transformación y sin que la generosidad de las palabras se transforme en fuerza social capaz de poner en jaque el orden dominante. Más aún asombra que ante este desconcierto la intelligentzia local (con contadas excepciones) se limite a repetir el estilo de cuestionamiento teórico a que dio origen la tradición marxista occidental. En caso contrario, el debate se rebaja al nivel de una defensa del nacional-populismo, que si bien produjo alguna unión feliz con el marxismo, en la tradición de Mariátegui, donde se pueden plantear cuestiones relativas al papel de las clases medias y al antimperialismo, como lo hizo el propio Haya de la Torre en su fase precínica, en general termina empantanada en la oposición latente entre lo "nacional" (pensado como "Estado", incluyendo las Fuerzas Armadas) y lo "popular", nunca pensado como algo concreto, y por lo tanto siempre frágil frente a la crítica de aquellos que en nombre de la "clase" (en general obrera) lanzan todo pensamiento nacional populista por el desvio de una posición de mera capitulación frente a las verdaderas tareas de la revolución.

No quiero cometer la injusticia de negar apresuradamente la originalidad y la fuerza de un sinnúmero de propuestas políticas ( y 
ciertos caminos) planteados en América Latina para resituar la cuestión de los países de la región en la órbita internacional y para promover las transformaciones necesarias en la estructura social. Prácticamente no existe ningún país latinoamericano que haya pasado los años 30 y los años 80 en el limbo sin que algún pensamiento y alguna acción de izquierda (independientemente de la coherencia del primero y de la eficacia de la última) se hayan perfilado en su horizonte. Pero en ninguno de ellos fue posible replantear la cuestión nacional, la cuestión popular y la cuestión democrática ante la etapa de desarrollo social y económico a que dio origen la internacionalización del sistema productivo, con la industrialización de algunos países latinoamericanos, o, en una palabra, con la oligopolización de las economías locales, hecha posible por la presencià activa de las empresas estatales y por la integración de las burguesías locales a las fuerzas oligopólicas dominantes.

En otras palabras, las experiencias de izquierda, tanto prácticas como teóricas, se definen de un modo u otro en el contexto de una situación histórica en que el "desarrollo nacional", las tareas de fortalecimiento del Estado local para servir de coraza contra la "penetración imperialista" y la definición de un -contorno más nítido para las "clases populares", dotándolas de una capacidad de acción política, si no autónoma, por lo menos reactiva frente a la expoliación económica y social, fijaron las líneas maestras del escenario político.

En este contexto, la relación entre partido (pensado en general como la forma política por excelencia para la articulación, fuera del Estado, de los intereses de una clase, y como vector para la existencia de un fundamento ideológico capaz de establecer una solidaridad en situaciones concretas heterogéneas) y movimiento social, por un lado, y entre este último y el Estado, por otro, constituyeron el meollo de la reflexión política de la izquierda.

Sólo rara vez hubo correspondencia entre esta visión (clásica, europeizante) y la práctica política: el Estado y los movimientos sociales fueron más fuertes que el partido. Las excepciones tal vez fueron más visibles en Chile, donde fue más lineal la corresponden. cia entre la estructura social (definida en términios de una situación de clase constituida en moldes asimilados al europeo de la fase del "capitalismo competitivo" y la estructura política: el partido comunista, el partido socialista (menos claramente), el partido radical y el partido nacional (o cualquiera que fuese el nombre del partido de los conservadores) y, más tarde, el partido democratacristiano, funcionaban a. la- europea. Si Marx hubiera nacido de nuevo como chileno, habría tenido la ilusión de que seguía en el siglo xrx, por lo que no habría sido necesario producir una nueva sociología y una nueva política: todo estaba explicado en El Capital. 
En Argentina, hasta la década de 1970, con la gran incógnita del peronismo como fórmula política, se veía también con cierta claridad la lucha entre (por así decirlo) el "lado clásico" de América Latina y la fuerza de un movimiento que expresaba un partido (con $\mathrm{p}$ minúscula) de corte heterodoxo. No obstante, el movimiento obrero y el sindicalismo sirvieron como campo magnético para la definición de la política de la izquierda, y por lo tanto las categarías generales del pensamiento marxista occidental tuvieron una base sobre la cual apoyarse. La lucha ideológica se suscitaba, precisamente, en torno al peso relativo del componente "de clase" de la política de la izquierda y a su componente nacional-obrera, incluso más que simplemente nacional popular. En Uruguay, sin la fuerza del peronismo y sin la orientación clasista de los partidos de izquierda en Chile, existía también hasta los tupamaros y el golpe militar, cierta correspondencia lineal entre partido y clase. A pesar de que allí la clase predominante en términos populares era la "media", el Estado fue sensible a sus intereses desde los tiempos de Batlle, y la oligarquía rural-exportadora se reconcilió con este sistema: el control político era ejercido por partidos constitucionales capaces de sentarse en la misma mesa para repartir en ella (desigualmente) la torta colectiva.

Fuera de estos tres países del Cono Sur, los ejemplos de reproducción de situaciones "clásicas" (denomino aquí "clásicas" las situaciones que se asemejan a una mezcla muy empobrecida del abanico de formaciones político-sociales que abarcó de Inglaterra a Francia y duró hasta los años sesenta) se dieron apenas en remedos menores, en el caso de países como Costa Rica, o en períodos cortos, en varios otros países de la región. En el resto, el Estado pesaba más que el partido o que el movimiento social.

No se trata en este capítulo de hacer grandes consideraciones sobre la naturaleza de clase y. el tipo de control político ejercido por el Estado latinoamericano, entre otras razones porque éste varió de país en país y de período en período. En lo que se refiere a Brasil y México, los dos mayores países de la región (en cuanto a población y a peso económico), se caracterizan, aunque por vías diversas, por la macrocefalia estatal. En el México postrevolucionario, y más específicamente, posterior al periodo de Cárdenas, hubo una vinculación importante en sus inicios entre el "moovimiento social" (obrero, campesino, intelectual) y el partido. Paulatinamente, se estableció la vinculación entre este último y el Estado.

A nadie relativamente informado sobre la historia social y política del México moderno se le ocurriría pensar que el partido carece de raíces profundas en la sociedad y en los estratos populares. Por el contrario, en él se integran el movimiento campesino, los trabajadores y los empresarios. $\mathrm{E}$ incluye gran parte de la intelectualidad, incluso la de sectores progresistas. A pesar de ello, es di- 
fícil describir el partido (me refiero, evidentemente, al PRI) como polo aglutinador de la sociedad civil, "a la europea". No deja de serlo, pero el encabalgamiento entre Estado y sociedad es de tal naturaleza que se hace difícil pensar en la oposición "liberal" entre la sociedad civil (el mercado) y la política (el Estado). En este contexto, el partido cumple funciones de puente y de reemplazo. Vincula, da curso y emite señales, de tal forma que los dueños del poder sintonizan con quienes tienen acceso a él, los que pueden tener alguna voz, pero no voluntad decisoria. En ningún caso organiza el partido la voluntad popular para que ésta controle el poder mediante el mecanismo de la representación. Organiza sí la masa; expresa, sin la fuerza de la representación para la constitución de las fuerzas de soberanía, el interés segmentado de la masa; pero es una entidad complementaria del Estado. $Y$ es este último quien dispone de los instrumentos que hacen bajar el puente levadizo entre el "electorado", la masa, la "ciudadanía" y el Estado. Electorado y ciudadanía llevan comillas porque en este tipo de sociedad el significado efectivo del voto y de la supuesta condición de miembro del cuerpo político de la nación no implican, de hecho, un ejercicio soberano de la voluntad, ni aún como ficción.

En el caso mexicano, este modelo de organización política, que utiliza el mismo lenguaje que el europeo del siglo $x I x$, pero que en la práctica se aparta de él, aunque conservando ciertos puntos de contacto (porque en algo pesan las semejanzas de lenguaje), parece como más desarrollada que los de otros países de la región, porque se institucionalizó, y porque esto se hizo a base de luchas sociales y de concesiones democráticas a los intereses populares. Sin embargo, la matriz política de situaciones como la brasileña posterior a 1964 y anterior a 1946 es la misma, sólo que, no habiéndose producido en el Brasil de hecho una revolución, sino contrarrevolución, y siendo más débil la integración política del Estado, o mejor del régimen autoritario, con la masa y con las clases medias, no se Ilegó a ninguna forma institucional de unión entre el Estado y el partido.

Antes de hacer comentarios más específicos acerca del Brasil, conviene señalar que en el caso mexicano la simbiosis Estado-partido es tan perfecta que incluso existe una especie de estado larvario y de metamorfosis del partido. Este se rehace y se metamorfosea en dos momentos contiguos: en el período que antecede a la elección del Presidente y en la fase "electoral". No se trata de que el partido tenga un peso decisivo en la elección del sucesor. Como se vio en forma espectacular recientemente en la indicación del señor De la Madrid para suceder a López Portillo, ésta depende de la voluntad presidencial, previas consultas a los dueños institucionales del poder: las empresas, la burocracia, la cúpula sindical y las fuer- 
zas armadas. Pero el rito de transición depende de un cuadro partidario "bien puesto". Un año antes de la elección, el partido comienza a temblar: en él se gestarán los elementos de segunda línea. decisoria y parte de los de primera línea. Se abren los canales, no entre el Estado y el pueblo, o entre el Estado y la sociedad, sino entre el partido y la sociedad. El partido sirve alli de dique para las ambiciones en la máquina estatal, de vivero para nuevas vocaciones burocráticas-políticas, de tamiz para la selección de intereses. Más adelante, con las alas desplegadas, el partido vuela como mariposa alrededor del foco del poder, el nuevo Presidente. Pero no es sólo una mariposa; es también un instrumento efectivo que va cimentando la unión del nuevo príncipe con sus "bases". En la campaña electoral, cumple con la función clave de dar a conocer la plataforma presidencial a la masa y de dar al pueblo la ilusión de que es soberano. Como la plataforma registra reivindicaciones sentidas por la masa, y como, en general, la retórica del candidato es "de oposición", vuelven a haber esperanzas de cambio y se sustituye el proceso efectivo del ejercicio de soberanía popular por un espejismo en que el pueblo ve reflejadas (aunque no representadas ni delegadas) algunas de sus reivindicaciones y objetivos.

Una vez elegido el Presidente, el partido vuelve a invernar, cediendo unà parte de sus cuadros (los más importantes y expresivos en la ligazón con los grupos de intereses) a la máquina del Estado. Ésta, a partir del primer año del sexenio, engorda y brilla hasta el año anterior a la nueva sucesión, en que el PRI despertará de sus cenizas, como Fénix de los Andes.

En el caso brasileño, especialmente después del régimen militar, la forma del partido es mucho más débil que en México. Ni el partido ni el movimiento social cuentan en la estructuración del Estado. Si el PRI es un partido que sirve de puente levadizo y se metamorfosea en el metabolismo político resplandeciendo e invernando alternativamente, en el Brasil el partido (incluso, o principalmente, el de Gobierno) es un partido ornamento. El sistema de poder no da bases para los partidos, aunque ellos desempeñen también importantes funciones legitimadoras (autentificadoras, en verdad) del género notarial o del género "comité electoral".

En el periodo de bipartidismo (de 1966 a 1978), el partido oficial, ARENA, era prácticamente una extensión de la máquina burocrática y del sistema real del poder, que tenía sus raíces en las fuerzas armadas (y represivas), en las grandes empresas y en la burocracia. Obedecía instrucciones superiores y apenas si servía como simulacro en el período electoral. Poco a poco, sin embargo, la dinámica de la sociedad brasileña -en franca expansión y movilidad gracias al desarrollo capitalista, oligopólico, estatal y privado- actuó sobre el núcleo de poder como un río en creciente, que sale de 
su lecho, crea nuevos brazos, separa las islas, y se lleva en la confusión de su torrente la masa mal sedimentada de tierra de aluvión. Así comenzó a existir como partido el de oposición, $\mathrm{MDB}$, fuera del límite estrecho de las funciones autentificadoras que le habían conferido los dueños del poder.

Terminado el bipartidismo, actualmente se aprecia la tentativa de crear partidos capaces de articular los intereses de la sociedad civil, tratando de transformarse en expresión organizada de la sociedad, según la moda europea. Hasta qué punto lo conseguirán (cualesquiera de ellos) es la incógnita que en el fondo tiene que ver con la cuestión principal de este capítulo: en este continente que salta del sistema patriarcal, del caudillismo y de las clientelas a una forma peculiar de "sociedad de masas" (mimética y pervertida en relación al modelo que en su caso, es más americano que europeo), chabrá acaso espacio para partidos relativamente homogéneos, con cierta consistencia ideológica, que se funden en la existencia no sólo de la ciudadanía, sino también de la clase social como pilar de representación política? Si así fuera fuera, ¿hasta qué punto podría servir de polo catalizador de percepciones, sentimientos e intereses la experiencia socialista (y comunista) europea?

No quiero adelantar reflexiones en torno a la respuesta de esta pregunta sin antes comentar, en algunos párrafos, otras situaciones latinoamericanas, y sin introducir en el análisis el argumento de orden estructural que me parece necesario para dar consistencia al debate.

En ciertos países ajenos al Cono Sur - Venezuela, por ejemplotambién se trasplantó con éxito la variedad europeo-occidentalizada de los partidos. Dejando de lado la ramificación de los partidos comunistas (flores de invernadero, apoyados por el peso de la gravitación mundial de la experiencia soviética, $y$, en menor proporción, de la china), diría que hubo dos o tres semillas de partidos que echaron raices en el suelo latinoamericano. Una de ellas fue la del estilo "demócrata cristiano". Ésta, aunque en menor grado, también floreció en invernadero, esta vez la Iglesia Católica, y de la ansiosa búsqueda de un "tercer camino", estimulada por el clima de guerra fría de los años cincuenta. La otra, más propia de la región, fue la mezcla de un partido oriundo de la fúsión del sentimiento democrático (extensión de la ciudadanía) coñ el nacionalpopulismo o con lo popular. Me refiero al APRA peruano y a sus similares en América Central y en Venezuela. La Acción Democrática venezolana, así como el partido de Figueres en Costa Rica, son fenómenos interesantes, bien o mal, apartándose de los estrechos moldes socialistas o liberales, se constituyeron como partidos "de la clase media", pero con profunda penetración popular en la ciudad y el campo. Desde este ángulo, son más ilustrativos que los parti- 
dos-movimientos, de tipo MNR boliviano, o del tipo Partido Liberal (renovado), constituido por el gaetanismo colombiano: se estructuraron mejor y en situaciones sociales y políticas más complejas, escapando del dilema colombiano, que acabó por aplastar la tentativa gaetanista en el remedo populista de Rojas Pinilla y en la consolidación del pacto liberal-conservador, de corte puramente oligárquico, que no puede ser expresión de modernos partidos de masas. En el caso del MNR (que se repitió en el tiempo en Bolivia, y tuvo núcleos correspondientes en el Ecuador), la presencia de fuertes cristalizaciones de la clase obrera y de una pequeña burguesía radicalizada, en el océano de una sociedad agraria, segmentada en castas y tradicional, dio origen a partidos de corte clasista, pequeños, disciplinados y limitados por su alteridad respecto del conjunto de la vida nacional.

Así, y aparte de los casos de partidos surgidos en situaciones más próximas a las europeas, son pocos los casos de partidos que agrupan a la masa y que buscan. la representación de sus intereses y que tienen fuerza nacional: el APRA, la A.D* y otros similares (que guardan, a su vez, algún punto de contacto con el PRI, con Ia diferencia esencial de que jamás se fundirían con el Estado en cuanto tal, como hace dicho partido) .

Cabe pues plantearse la siguiente pregunta: ¿no estaremos acaso pidiéndole peras al olmo, persistiendo en buscar una forma clásica de partido (de derecha, de centro o de izquierda) en circunstancias que las sociedades de "nuestra América" tienen otro estilo de hacer polftica, otras instituciones y otra dinámica?

En este punto, cabe a las izquierdas una reflexión más madura acerca de cómo hacer la teorfa política y la acción transformadora en América Latina, y cuál puede ser el efecto de la experiencia política socialista francesa, no con el afán de transplantarla al suelo poroso y retorcido de nuestras sociedades, sino de extraer de ella las inspiraciones pertinentes.

No es preciso alargarme mucho para explicar lo que está entre líneas en páginas anteriores: la forma clásica de partido, tanto la de los partidos comunistas como la de los partidos socialdemócratas, de vanguardia revolucionaria o democráticos de masas (sean o no también comunistas, como en Italia) encuentra resistencias no en la costra ideológica, sino en realidades estructurales latinoamericanas. Existió como realidad, y persiste como posibilidad, en Ios países cuyas economías se organizaron en forma capitalista y se urbanizaron de acuerdo con el modelo del "capitalismo competitivo" Una vez que la presencia del Estado y de los grandes conglomera-

* Cabe notar que en Venezuela se presenta también, tras la crisis de legitimidad de la A. D., y luego la guerrilla, la única forma más creativa de "socialismo mestizo": el Mas (Movimiento al Socialismo). 
dos comenzó a dar el rumbo de la sociedad, la movilización de masas, la generalización de las expectativas de participación y la ruptura de los diques del mundo agrario de la hacienda, así como las migraciones internas y los procesos de movilidad social, pusieron en jaque los equilibrios anteriores, ya sea "oligárquico-tradicionales" o bien correspondientes a las fórmulas del "Estado de compromiso", para utilizar los términos de Medina Echavarría y de Francisco Weffort. Germani y Touraine también percibieron este fenómeno: ni el nacional-populismo fue fascista, según el primero, ni la industrialización y la urbanización tendrían los efectos típicos de clase que se dieron en las sociedades industriales del pasado, en opinión del segundo.

En Ia transición, durante el período que va desde el fin de la Segunda Guerra a la reordenación del espacio socioeconómico mediante la producción internacionalizada, varias experiencias democratizantes adoptaron formas diferentes, según cual fuera el crisol histórico del cual provenían: desde el partidismo redivivo en Chile, durante los gobiernos de Frei y de Allende, pasando por la guerrilla, hasta los movimientos de "liberación nacional" del Caribe y de Centroamérica. En esta transición (que como toda transición histórica es abierta en cuanto a sus resultados), algunos países se sumergieron en la gran lucha global de los dos (o tres o varios) campos. Cuba se hizo socialista e ingresó a la órbita soviética; Nicaragua escapó de las redes americanas, al igual que la pequeña Granada; en EI SaIvador la lucha todavía prosigue; en Santo Domingo se produjo Ia invasión estadounidense y posteriormente el armisticio socialdemócrata; en Guatemala, el aplastamiento de la revolución democrática por la presión y acción de la derecha local e internacional; en Panamá y en Perú predominó un militarismo "progresista", en un sentido nacional, y, en la mayoría de los países grandes del Sur, se impuso la álgida perversión burocrático-autoritaria de los regímenes militares.

En la actualidad (con excepción de los países que se separaron de la órbita americano-occidental o de aquellos que por la estrechez de sus mercados no dan margen al nuevo proceso) es otra partitura la que marca el compás de la música: Estado y gran empresa, militares y burócratas de Ia administración o de las empresas, proyectan un enorme cono de sombra sobre las expectativas de que el patrón de las sociedades nacido en el terreno de la competencia entre capitalistas individuales (por grandes que fueran) y en el liberalismo pueda marcar los límites del futuro. La industrialización oligopólica, la internacionalización de la producción y de la cultura, el surgimiento de fuertes segmentos de una "economía de servicios", Ia presencia activa de los medios de comunicación de masas; la formación, en una palabra, de un estilo de sociedad de masas que no es precisamente igual a los de las sociedades de las "clases 
industriales" del pasado europeo, y el reforzamiento de una dominación de clase encastillada en un estado que prescinde de los partidos y se apoya, cada vez más, en el freno a la ascensión de masas representado por las Fuerzas Armadas, en la segmentación creciente de los intereses de las clases subalternas y en la manipulación cultural de los estilos de vida y las aspiraciones de consumo, nos obligan a repensar las formas de política.

Sería ingenuo imaginar que "la fórmula socialdemócrata" podría tener éxito, en la izquierda, allí donde fracasó la "fórmula bolchevique": ambas son variantes de un mismo mundo que no es el mundo latinoamericano. Ambas suponen una extensión, un peso y un grado de organización y de autonomía de las clases trabajadoras ante el Estado y las clases dominantes que no se aprecia en la vida diaria de este continente.

El lector tal vez se espante de una afirmación tan rotunda como ésta: sin embargo, tno fue acaso en los Estados Unidos, cuna del capitalismo oligopólico contemporáneo, donde los partidos de tipo europeo y los esfuerzos de los movimientos europeos de los años 20 y 30 . fueron tragados por la voracidad de una sociedad dinámica, impregnada de la más pura filosofía individualista, stateless, y que dio origen a una democracia sin partidos (en sentido clásico), basada en la Constitución, en los derechos individuales, en las máquinas partidarias, en el "spoil-sytem" que vincula a éstas al Gobierno, y en el comité electoral como forma casi exclusiva de presencia del partido en. la sociedad? ¿Por qué, entonces, sería preciso imaginar necesariamente que el desarrollo de la economía internacionalizada tendría que echar en la sociedad latinoamericana bases de sustentación para los partidos democráticos de masas, ideológicos, cimientos de la cultura política, puente entre la sociedad y el Estado, entre el individuo y las instituciones políticas?

No obstante, Brasil o México (para referirse solamente a los países latinoamericanos que más avanzaron en la dirección de la forma social antes señalada) no son Estados Unidos. No propongo que se descarten las fórmulas de los partidos comunistas y de los partidos socialdemócratas en favor de otras basadas en Ios comités electorales, del tipo-del Partido Demócrata de los Estados Unidos.

La realidad es más compleja. Basta leer los capítulos que siguen para ver que los clubes socialistas, los congresos de la Fsio o del Ps, la polémica entre los eurocomunistas y los socialistas franceses, el estilo de alianza de tipo Frente Popular, el Programa Común -en resumen, las instituciones y eventos que marcaron la evolución de la izquierda francesa - tienen poco que ver con los acontecimientos significativos de la vida política latinoamericana. Pueden incluso producir envidia y hacer que se les haga agua la boca a los más cultos y occidentalizados de los latinoamericanos. Pueden inspirar re- 
vistas $\mathrm{y}$ artículos de izquierda. Pero difícilmente se aproximan en la práctica a los partidos aquí existentes y que tienen capacidad de galvanizar energías en procura del poder.

Sin embargo, precisamente porque también en Francia el gobierno de Mitterrand enfrenta el desafío del poder tras el período del degaullismo, tras la monopolización de la economía y tras el agigantamiento de las burocracias públicas; y porque también en Francia la clase obrera ya no es la misma, sin que por ello haya dejado de ser decisivo el voto obrero y popular, el socialismo francés deberá resolver, en el poder, ciertas cuestiones que tienen puntos de contacto con el desafío actual en América Latina, o al menos en los más desarrollados de sus países.

Sin que sea necesario adoptar el vocabulario de Touraine y sin provocar por ello reacciones alérgicas en las personas más habituadas a razonar en los términos del vocabulario clásico, es obvio que no se resolverá la cuestión de "qué tipo de socialismo" en Francia (y tampoco aquí), si la lista de transformaciones estructurales 6e. limita a la cuestión de las nacionalizaciones de los grandes monopolios. La desconfianza respecto de que las burocracias (incluso las públicas, incluso las socialistas) contienen un germen de sofoco y de autoritarismo está muy generalizada hoy en día. La mera solución estatizante no será suficiente en Francia (como no lo fue en Polonia) ni tampoco en América Latina.

Sin embargo, en este continente de opresión social, existe también y cómo! la cuestión nacional. No bastan las consignas libertarias antiburocráticas. Es preciso entender que la acción del Estado, que incluye las nacionalizaciones, formará parte del programa socialista. Pero habrá que dar un salto: la acción ha de ser públi$c a$, más que estatal. Lo que quiere decir controlada por los usuarios de los servicios, por los consumidores de las mercaderías producidas por el sector estatal de la economía, por los obreros que sustentan la producción, por los ingenieros, los técnicos, los administradores. No hay forma de eludir la cuestión: el socialismo moderno exige (más aún que la utopía del "fin del Estado") una teoría y una práctica de control democrático del Estado por parte de la sociedad. ¿Dará Francia un ejemplo de ello?

En el reverso de la medalla, la democracia que convivirá con el socialismo (con más fuerza aún en el continente de la opresión social) debe superar (en el sentido hegeliano, conservando en la síntesis lo que había de positivo en la contradicción anterior) la base estrecha del individualismo burgués (posesivo) y la noción de que es democrática la sociedad que transforma sus instituciones para dar origen al "mercado político", en el cual la mano invisible del interés, la voluntad y el voto individual realiza el "bien común". Ciertamente, el Estado de Derecho, las garantías individuales, los 
derechos humanos, la urna y las elecciones han de ser componentes esenciales de la democracia socialista. Mas la filosofía política será menos liberal y más democrática, popular.

En nuestra América, cuando se salta de la sociedad patrimonial, de larga tradición y penetración corporativista, a la sociedad oligopólica de masas, la transición hacia un estilo de democracia que eche raíces en lo social, más que en lo individual, es tal vez más fácil que en Europa. Pero el recorrido es difícil, si se desea escapar del corporativismo y del estatismo manipulador. La falta de tradición liberal (paradojal, aunque comprensiblemente), hace que los cimientos de la democracia se construyan con una mezcla de poca consistencia.

En este punto entra en escena el otro componente del socialismo democrático contemporáneo: si no fuéramos capaces de entender que las formas estatales y partidarias (cualesquiera que sean) tienden a aplastar el componente de espontaneidad de la sociedad y la autonomia de los movimientos sociales, nos arriesgaríamos a caer en el burocratismo, por nobles que sean los ideales políticos existentes tras las victorias de los partidos que se oponen a la sociedad oligopólica de masas. En Francia, el ps de Mitterrand ensayó algo nuevo en la campaña electoral: el movimiento feminista, los grupos ecológicos no adhirieron al Programa Cơmún como quien espera de él la salvación. Algunos de estos movimientos apoyaron al partido socialista en la convicción de que un Gobierno socialista abre espacios para que se articule la gran escena de los movimientos sociales. No alienaron su voluntad delegándola en el partido.

La tensión y la dialéctica entre Estado y movimiento, entre partido y acción no comprometida, es constitutiva de la vida contemporánea. El Estado y los partidos son necesarios para la organización de la acción colectiva. Esto es aún más evidente en los países dependientes (donde se impone la cuestión nacional) y pobres (donde prima la cuestión social) Sin embargo, pensar que ellos "dirigirán", serán "hegemónicos", sin contrapesos, en la conducción del proceso político, nos lleva al riesgo inminente del totalitarismo. Por otra parte, la "sociedad civil", como se llama imprecisamente todo lo que hace presión y política sin ser de modo inmediato un agente institucional del poder (los sindicatos, las iglesias, las universidades, los grupos de pobladores o el pueblo), exige espacios de libertad para que haya democracia.

Sin embargo, pensar que la sociedad socialista se organizará a partir de la propia espontaneidad del "movimiento" o de la "base" es incurrir en el riesgo (o en la certeza) del anarquismo, que es impotente e inconsecuente frente al modo de producir y vivir en las sociedades contemporáneas, industriales y de servicios.

Esta cuestión se plantea en Francia. De su resolución o falta de ella dependerá en gran parte la influencia que podrá ejercer el so- 
cialismo francés en América Latina. ¿Será capaz de unir la "revolución cultural" de las sociedades avanzadas y la acción pública? ¿La fuerza de los movimientos colectivos con la acción disciplinante de los partidos y del Estado? ¿Los derechos individuales con la noción de bienestar colectivo?

Sin embargo, no es sólo en el nivel de la ideología y de las estrategias politicas que la experiencia de. Mitterrand podrá ser importante para el socialismo de América Latina. También lo será en el plano propiamente político, de las alianzas de clases.

Difícilmente podría decirse que el partido socialista es un "parr tido obrero". El partido comunista lo es mucho más. Los socialistas sacan su fuerza electoral y política de otra tradición: son fuertes en Francia entre el profesorado secundario y superior; entre los profesionales (ex liberales) univensitarios y los técnicos; entre los artistas; en parte del empresariado no oligopólico y aún marginal a la producción moderna; en la gran masa de asalariados denominados "de clase media". Y, también, entre sectores de trabajadores.

Esta amalgama de clases, que para el juicio crítico de la vieja izquierda sería la debilidad de los socialistas, es precisamente su fuerza. La sociedad francesa es actualmente otra, aunque esté llena de marcas de la estructura de clases del período que precedió a la nueva fase del capitalismo oligopólico. En la nueva sociedad, los obreros son parte importante, pero en declinación numérica*. $Y$ se vinculan, por su educación, por su modo de vida, por necesidades $y$ luchas comunes, con el gran mundo de los asalariados urbanos. La base de la nueva sociedad incluye los técnicos y los profesionales entre los productores directos. Los partidos que se aíslan en la antigua clase obrera perderán capacidad de agregación. El partido socialista dio el salto. Lo dio correctamente: asumió como parte integrante de la alianza transformadora a la clase obrera; no la erigió en mito ni se atuvo a sus límites; no tuvo pretensiones: entendió que el partido comunista (en Francia) tenía profundas raíces en el proletariado. Mezcló las propias con las de dicho partido.

En América Latina no existe (con las excepciones ya señaladas) la tradición de un partido comunista fuerte. La clase obrera (especialmente en los países de "nueva industrialización") nace al mundo en el siglo xx, en la dirección del xxi. Se mezcla al resto de los asalariados. Aquí, los focos históricos, herederos de las esperanzas de redención de la humanidad por la revuelta de los desposefdos, serían otros: los "campesinos", los "marginales". El desafío para el socialismo latinoamericano no consistirá tanto en unir lo que en lenguaje corriente se llama clases medias con los obreros (cosa

\footnotetext{
* Ver datos al respecto en Cardoso, F. H., "As clases nas sociedades capitalistas contemporaneas", Revista de Economía Política, São Paulo, 2 (5) :5-28, enero/marzo 1982 .
} 
que es fácil), sino unir estos dos sectores con el resto de las clases populares.

En este sentido, nuestro sociàlismo será aún más heterodoxo que el francés: se bautizará para buscar en las comunidades eclesiales de base y en el movimiento social del campo la savia necesaria para ser popular, y se racionalizará para atraer el apoyo de los sectores que saben hacer funcionar el mundo productivo moderno y el Estado.

Hic Rhodes; hic salta. Hará esto, si fuera posible, pues la "barbarie" en nuestro continente está a la vista. Está en el nuevo Estado, el de las burocracias y de las empresas transnacionales, que es capaz de registrar la demanda popular, y devolver sus deseos con gotario, despojados de su nervio político, como mecanismo de control y no como liberación. Y al decir Estado digo también Gran Capital, puesto que en las sociedades de "libre empresa" (cada vez más regulada y menos individual) el uno no existe sin el otro. 